\title{
Comparison of the welfare of laying hens, broiler chickens and turkeys in terms of bird health as surveyed during inspection in slaughterhouses
}

\author{
Lenka Večerková, Eva Voslářová, Vladimír Večerek \\ University of Veterinary and Pharmaceutical Sciences Brno, Faculty of Veterinary Hygiene and Ecology, \\ Department of Animal Protection, Welfare and Behaviour, Brno, Czech Republic \\ Received February 24, 2019 \\ Accepted April 23, 2019
}

\begin{abstract}
During the period 2010-2017 we monitored 17346183 laying hens, 887994167 broiler chickens and 919843 turkeys slaughtered at slaughterhouses in the Czech Republic. In cooperation with the State Veterinary Administration, we recorded findings detected in slaughtered birds within the post mortem veterinary inspection. We analysed the total number of patho-anatomical findings (of intravital origin) and the number of findings divided into acute, chronic and traumatic diseases. In hens, the total ratio of the number of patho-anatomical intravital findings to the number of slaughtered birds (index) was found to be 0.378 . This index of the incidence of pathoanatomical findings in hens was higher $(P<0.001)$ than that found in broilers $(0.016)$ and turkeys (0.101). The prevailing findings in hens were chronic changes $(26.32 \%)$, followed by acute changes $(5.29 \%)$, but also notable were traumatic changes $(3.90 \%)$. Compared to the findings in broilers which were divided into chronic $(0.34 \%)$, acute $(0.10 \%)$ and traumatic diseases $(0.02 \%)$ and turkey findings which were broken down into chronic $(7.60 \%)$, acute $(0.16 \%)$ and traumatic diseases $(0.33 \%)$, the findings of acute, chronic and traumatic diseases were higher $(P<0.001)$ in hens than in broilers and turkeys. These findings show that the health condition and hence the welfare of laying hens as reflected in the patho-anatomical findings during the veterinary inspection of slaughtered birds is significantly worse than the health condition of broilers and turkeys. This demonstrates the need for increased care for laying hens both on farms and in transit to the slaughterhouse.
\end{abstract}

Poultry, slaughter, meat inspection, patho-anatomical findings

Meat inspection is one of the most widely implemented and longest running systems of veterinary surveillance. Its primary objective is to identify animals that are not fit for human consumption and to remove their carcasses and offal from the food chain. Additional objectives are to support animal disease control and to identify and prosecute animal welfare issues (Stark et al. 2014). Findings from the veterinary inspection of animals slaughtered in the slaughterhouse document the impact of the conditions of breeding, animal care and handling during the rearing and transport to the slaughterhouse on the animals. The long-term total value of the veterinary inspection findings regarding slaughtered animals document the level of animal health, thereby proving the level of animal welfare on farms and during their transport to the slaughterhouse.

Post mortem findings in slaughtered animals reported in literature focus mainly on the protection of human health regarding the disposal of whole carcasses, organs or tissues in terms of hygienic standards and safety of meat and other products for human consumption.

Several studies attempted to identify and quantify condemnation of poultry carcases at slaughterhouses (Radkowski et al. 1996; Ansari-Lari and Rezagholi 2007; Santana et al. 2008; Lupo et al. 2010; Ferreira et al. 2012; Ghaniei et al. 2016; Salines et al. 2017).

However, the findings detected in animals slaughtered in slaughterhouses can also be assessed from the perspective of animal welfare. Such focus can be found in the studies

Address for correspondence:

Doc. Ing. Eva Voslářová, Ph.D.

Department of Animal Protection, Welfare and Behaviour

Faculty of Veterinary Hygiene and Ecology

University of Veterinary and Pharmaceutical Sciences Brno

Palackého tř. 1946/1, 61242 Brno, Czech Republic 
by Sanchez-Vazquez et al. (2011), van Staaveren et al. (2017), Carroll et al. (2018), and in a study on poultry by Grilli et al. (2015). A change in health, animal damage or a significant change in animal welfare is seen as an intravital change on the body, organs and/or animal tissues as a patho-anatomical finding. Assessing the findings from the slaughterhouse from this point of view creates an additional image of the level of health, animal damage and/or well-being, and it reflects the overall picture of animal health and fitness. Such a view of the evaluation of the findings on animals slaughtered in slaughterhouses is insufficient in the available literature.

The aim of this study was to compare the occurrence of patho-anatomical findings in laying hens with the numbers found in broiler chickens and turkeys. A further aim of the work was to compare the number of patho-anatomical findings divided into acute, chronic and traumatic diseases in laying hens with the numbers found in broiler chickens and turkeys. Another objective was to identify trends in the development of health and welfare during the monitored period. On the basis of these results, we assessed whether the level of health status and related welfare of laying hens was lower or higher than that of broiler chickens and turkeys and whether it was changing over the years.

\section{Materials and Methods}

During the period 2010-2017, we monitored all poultry transported for slaughter from farms to slaughterhouses within the Czech Republic, i.e. 17346183 laying hens, 887994167 broiler chickens and 919843 turkeys slaughtered in Czech slaughterhouses. In cooperation with veterinarian officials (State Veterinary Administration of the Czech Republic), we recorded patho-anatomical findings in slaughtered laying hens, broiler chickens and turkeys detected during the veterinary inspection after slaughter in the slaughterhouse.

We investigated the total number of patho-anatomical findings of intravital origin. From the obtained data, we calculated the number of patho-anatomical findings as the ratio of the number of patho-anatomical findings of intravital origin and the number of slaughtered birds. This value demonstrates the overall level of health of birds transported for slaughter. To assess the severity of the observed health condition of the laying hens transported for slaughter, the indices were compared with the indices of patho-anatomical findings calculated in the same way for broiler chickens and turkeys. The indices of the number of patho-anatomical findings were calculated for laying hens, broilers and turkeys both for the whole reference period together as well as for each of the years 2010 to 2017 individually.

Furthermore, we also investigated the number of patho-anatomical findings of intravital origin, divided into acute, chronic and traumatic diseases. We calculated the incidence of acute, chronic and traumatic changes in slaughtered poultry. These values demonstrate the level of bird health in terms of acute, chronic and traumatic illnesses. This observed health condition of laying hens was then compared with the health condition of broiler chickens and turkeys in order to determine whether the levels of health condition and associated welfare in laying hens was lower or higher than that of broiler chickens and turkeys.

The results were analysed using the statistical package Unistat 5.6. (Unistat Ltd., London, England). Statistical comparisons between the frequencies of categorical variables of interest were performed using chisquare test (with Yates correction) within the $2 \times 2$ contingency table procedure. When the frequencies in the contingency table were lower than 5, Fisher's exact test was used instead of chi-square test. To assess the trend during the monitored years, the Spearman's rank correlation coefficient including its significance was calculated. A $P$-value $<0.05$ was considered significant.

\section{Results}

The total number of patho-anatomical findings (of intravital origin) in laying hens, broiler chickens and turkeys is presented in Table 1. The index of the number of pathoanatomical findings in the post mortem poultry veterinary examination was significantly higher $(P<0.001)$ in hens (index 0.378) than the index of patho-anatomical findings in broiler chickens (index 0.016) and turkeys (index 0.101).

The numbers of patho-anatomical findings in hens slaughtered at slaughterhouses, subcategorized as acute, traumatic, and chronic findings are summarized in Table 2. The differences between findings of acute, chronic, and traumatic nature were significant $(P<0.001)$. Also the differences in the number of acute, chronic, and traumatic pathoanatomical findings between hens and broiler chickens and turkeys (Table 2) were 
Table 1. Comparison of the occurrence of patho-anatomical findings in laying hens with the total number of findings found in broiler chickens and turkeys.

\begin{tabular}{lccc}
\hline Poultry species/category & Laying hens & Broiler chickens & Turkeys \\
\hline $\begin{array}{l}\text { Number of slaughtered animals } \\
\begin{array}{l}\text { Number of patho-anatomical } \\
\text { findings - intravital }\end{array}\end{array}$ & 17346183 & 887994167 & 919843 \\
$\begin{array}{l}\text { Index of the number } \\
\text { of patho-anatomical findings ratio } \\
\text { to the number of slaughtered animals }\end{array}$ & 6550621 & 14347535 & 9251 \\
\hline
\end{tabular}

a,b,c - indices within a row with different superscripts differ significantly $(P<0.001)$.

Table 2. Numbers of patho-anatomical findings divided into acute, chronic, and traumatic diseases in laying hens $(n=17346183)$ compared to the numbers found in broiler chickens $(n=887994167)$ and turkeys $(n=919843)$ slaughtered at slaughterhouses.

\begin{tabular}{lrrrrrr}
\hline & \multicolumn{2}{c}{ Laying hens } & \multicolumn{2}{c}{ Broiler chickens } & \multicolumn{2}{c}{ Turkeys } \\
\hline Findings & number & $\%$ & number & $\%$ & number & $\%$ \\
\hline acute & 916892 & $5.29^{\mathrm{a}, \mathrm{y}}$ & 852013 & $0.10^{\mathrm{c}, \mathrm{y}}$ & 1429 & $0.16^{\mathrm{b}, \mathrm{z}}$ \\
chronic & 4565623 & $26.32^{\mathrm{a}, \mathrm{x}}$ & 3011690 & $0.34^{\mathrm{c}, \mathrm{x}}$ & 69898 & $7.60^{\mathrm{b}, \mathrm{x}}$ \\
traumatic & 676488 & $3.90^{\mathrm{a}, \mathrm{z}}$ & 208500 & $0.02^{\mathrm{c}, \mathrm{z}}$ & 3063 & $0.33^{\mathrm{b}, \mathrm{y}}$ \\
\hline
\end{tabular}

a,b,c - percentages within a row with different superscripts differ significantly $(P<0.001)$

$\mathrm{x}, \mathrm{y}, \mathrm{z}$ - percentages within a column with different superscripts differ significantly $(P<0.001)$.

significant $(P<0.001)$. Laying hens showed the highest number of all: patho-anatomical findings of acute, chronic, and traumatic nature.

The development of the number of patho-anatomical changes found during the veterinary examination in laying hens over the monitored period compared to those in broiler chickens and turkeys is shown in Fig. 1. We found a significant trend $(P=0.028)$ of decrease in

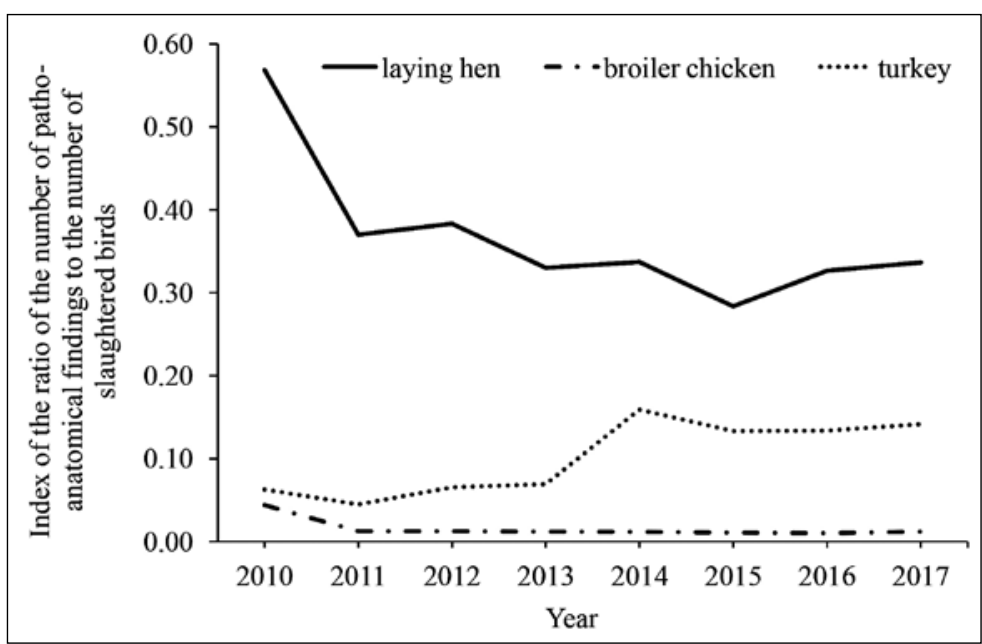

Fig. 1. The development of the ratio of the number of patho-anatomical findings to the number of slaughtered laying hens in individual years of the monitored period compared to trends in broiler chickens and turkeys. 
the ratio of the number of patho-anatomical findings to the number of slaughtered laying hens (index) expressed by the Spearman's coefficient of sequence correlation at the level of -0.762 . In contrast, we found a significant increasing trend $(P=0.010)$ for turkeys $(+0.833)$. For broiler chickens, a significant trend $(P=0.037)$ of decline $(-0.738)$ was found in the monitored period from 2010 to 2017.

\section{Discussion}

Animal welfare has become an important issue in poultry production (Bessei 2018) and the expectations of the society regarding the production of food are continuously rising (Sonntag et al. 2018). The level of poultry welfare during its rearing and transport to the slaughterhouse is a consequence of conditions on farms and during transport. These are reflected in the bird health condition, the standard of which is determined within the veterinary inspection of poultry slaughtered in slaughterhouses. The total number of pathoanatomical findings (of intravital origin) in slaughtered laying hens was investigated and compared with the total number of findings in broiler chickens and turkeys. The results include data from the veterinary inspection of slaughtered poultry (laying hens, broiler chickens, and turkeys) in the whole Czech Republic over a period of 8 years. Such data have not been published yet for other countries to a comparable extent. As Salines et al. (2017) pointed out, studies presenting findings at slaughterhouses are difficult to compare. Study samples vary greatly, they are often small and not randomly selected, and thus it is not certain if they reflect the situation for an entire poultry production at a national level. Indeed, most authors recorded and analysed the results of meat inspection only at one or more selected slaughterhouses and for a short monitoring period. Furthermore, most authors do not differentiate poultry species and categories. However, it is clear from the results of our study that there is a difference in the number of findings found between species and categories of poultry. The index of the number of patho-anatomical findings in the post mortem poultry veterinary examination was significantly higher $(P=0.001)$ in hens $(0.378)$ than the index of patho-anatomical findings in broiler chickens $(0.016)$ and turkeys $(0.101)$. This finding is an evidence of the fact that the health condition of slaughtered laying hens as reflected in the patho-anatomical findings found during the veterinary inspection at the slaughterhouses was significantly worse than the health condition of broilers or turkeys. Correspondingly, Radkowski et al. (1996) found the highest percentage of condemned birds in hens $(2.4 \%)$ in comparison with a lower frequency of condemned broiler chickens $(1.27 \%)$, and turkeys $(1.72 \%)$. An explanation for this may be the fact that laying hens are slaughtered after their utility potential has been exhausted and their previous intense use is reflected in their ability to cope with factors affecting the state of health during rearing, transport, and handling. On the contrary, broilers and turkeys represent young birds at the peak of their economic use, where the impact of rearing on their health is not so pronounced. They show a lower level of health damage and thus greater ability to cope with the effects of rearing, transport, and handling than laying hens. As a result, the lower welfare of laying hens on farms as well as during transport is obvious compared to the welfare of broiler chickens and turkeys.

Furthermore, we examined the numbers of patho-anatomical findings in slaughtered hens, divided into acute, traumatic, and chronic diseases, and we compared them with the findings in broiler chickens and turkeys. Laying hens showed the highest number of all: patho-anatomical findings of acute, chronic, and traumatic nature. Chronic pathoanatomical findings were found at the highest frequency in laying hens $(26.32 \%)$, which proves that these changes originated on farms rather than during the transport for slaughter. The housing systems in laying hen husbandry has undergone major changes in recent years. The ban on conventional cages was clearly motivated by efforts to increase the welfare of laying hens. However, as it turns out from a comparison of the welfare of laying hens in 
four housing systems in the UK, no single housing system is ideal from a hen welfare perspective (Sherwin et al. 2010). According to Lay et al. (2011), the management of each system has a profound effect on the welfare of the birds in that system; thus, even a housing system that is considered to be superior relative to hen welfare can have a negative effect on welfare if poorly managed. The right combination of housing design, breed, rearing conditions, and management is essential to optimize hen welfare, health, and productivity. Furthermore, Sherwin et al. (2010) found the high prevalence of emaciation, loss of plumage, fractures and evidence of stress across all housing systems and suggest that the welfare of modern genotypes is poor. Besides the findings of chronic character, the acute findings $(5.29 \%)$ as well as those of traumatic character $(3.90 \%)$ were also significantly $(P<0.001)$ more frequent in laying hens compared to broiler chickens and turkeys. The hens have fragile bones (osteoporosis) due to the decalcification of bones in their laying lives and are hence prone to fractures (Webster 2004). Previous studies have shown that as many as $29 \%$ of hens have broken bones by the time they reach the water bath stunner (Gregory and Wilkins 1989; Knowles and Broom 1990; Reed et al. 1993; Knowles 1994; Kettlewell and Mitchell 1994). The fractures may be caused at the time of removal from the cage and exacerbated by the carriage and passing of the hens from person to person during the depopulation of the house. The small opening in the transport crates may induce further damage to the hens while they are loaded (Kristensen et al. 2001). It is clear that current methods of depopulation of laying hens present a serious welfare problem and they have to be modified. Correspondingly, Grilli et al. (2015) concluded that the presence of recent traumatic injuries during a post mortem inspection could be a valid means to establish whether corrective measures concerning handling, transport and loading procedures should be taken.

Altogether, it is clear from the findings in the acute, chronic and traumatic breakdown that the number of findings of chronic, acute as well as traumatic character in hens is considerably higher compared to broiler chickens and turkeys. Such results illustrate a lower level of health as for chronic, acute and traumatic changes in laying hens, and thus a lower level of welfare in laying hens as compared to broiler chickens and turkeys.

A different trend was found in the numbers of patho-anatomical changes found during the veterinary examination in laying hens over the monitored period in laying hens, broiler chickens and turkeys. We found a significant decline in the ratio of the number of patho-anatomical findings to the number of slaughtered birds in laying hens and broiler chickens while a significant growth trend was found for turkeys in the monitored period. It can be considered a positive finding in relation to the development of health and hence the welfare of laying hens compared to turkeys in particular. Despite the evident decrease in the number of patho-anatomical findings found within the veterinary examination of laying hens in the slaughterhouse between 2010 and 2017, the number of patho-anatomical findings in laying hens was, however, up to several times higher in comparison with broiler chickens and turkeys.

In conclusion, the welfare of laying hens during their rearing and transport to slaughterhouses, reflecting the health condition of the birds, which was monitored during the veterinary inspection of slaughtered laying hens, is lower than the welfare of broiler chickens and turkeys. These findings illustrate the need for an increased care of laying hens during their rearing and transportation to slaughterhouses to increase the level of welfare of laying hens to the levels corresponding to those of broiler chickens and turkeys.

\section{Acknowledgments}

This study was supported by Internal Grant Agency of the University of Veterinary and Pharmaceutical Sciences Brno (Project No. 212/2018/FVHE). 


\section{References}

Ansari-Lari M, Rezagholi M 2007: Poultry abattoir survey of carcass condemnations in Fars province, southern Iran. Prev Vet Med 79: 287-293

Bessei W 2018: Impact of animal welfare on worldwide poultry production. World Poultry Sci J 74: 211-224

Carroll GA, Boyle LA, Hanlon A, Collins L, Griffin K, Friel M, Armstrong D, O'Connell NE 2018: What can carcass-based assessments tell us about the lifetime welfare status of pigs? Livest Sci 214: 98-105

Ferreira TZ, Sesterhenn R, Kindlein L 2012: Economic losses of main causes of condemnation of the broiler carcass in a slaughterhouse under Federal Inspection on Rio Grande do Sul, Brazil. Acta Sci Vet 40: 1021

Ghaniei A, Mojaverrostami S, Sepehrnia P 2016: Survey of poultry carcass condemnations in abattoirs of West Azerbaijan Province (North West of Iran). J Hell Vet Med Soc 67: 183-188

Gregory NG Wilkins LJ 1989: Broken bones in domestic fowl: Handling and processing damage in end-of-lay battery hens. Brit Poultry Sci 30: 555-562

Grilli C, Loschi AR, Rea S, Stocchi R, Leoni L, Conti F 2015: Welfare indicators during broiler slaughtering. Brit Poultry Sci 56: 1-5

Kettlewell PJ, Mitchell MA 1994: Catching, handling and loading of poultry for road transportation. World Poultry Sci J 50: 54-56

Knowles TG 1994: Handling and transport of spent hens. World Poultry Sci J 50: 60-61

Knowles TG, Broom DM 1990: The handling and transport of broilers and spent hens. Appl Anim Behav Sci 28 : $75-91$

Kristensen HH, Berry PS, Tinker DB 2001: Depopulation systems for spent hens - A preliminary evaluation in the United Kingdom. J Appl Poultry Res 10: 172-177

Lay DC, Fulton RM, Hester PY, Karcher DM, Kjaer JB, Mench JA, Mullens BA, Newberry RC, Nicol CJ, O'Sullivan NP, Porter RE 2011: Hen welfare in different housing systems. Poultry Sci 90: 278-294

Lupo C, Le Bouquin S, Allain V, Balaine L, Michel V, Petetin I, Colin P, Chauvin C 2010: Risk and indicators of condemnation of male turkey broilers in western France, February-July 2006. Prev Vet Med 94: 240-250

Radkowski M, Uradziński J, Szteyn J 1996: The occurrence of infectious and parasitic diseases in poultry slaughtered in the district of Olsztyn, Poland, 1986-91. Avian Dis 40: 285-289

Reed HJ, Wilkins LJ, Austin SD, Gregory NG 1993: The effects of environmental enrichment during rearing on fear reactions and depopulation trauma in adult caged hens. Appl Anim Behav Sci 36: 39-46

Salines M, Allain V, Roul H, Magras C, Le Bouquin S 2017: Rates of and reasons for condemnation of poultry carcases: harmonised methodology at the slaughterhouse. Vet Rec 180: 516

Sanchez-Vazquez MJ, Strachan WD, Armstrong D, Nielen M, Gunn GJ 2011: The British pig health schemes: integrated systems for large-scale pig abattoir lesion monitoring. Vet Rec 169: 413-U493

Santana AP, Murata LS, de Freitas CG, Delphino MK, Pimentel CM 2008: Causes of condemnation of carcasses from poultry in slaughterhouses located in State of Goias, Brazil. Cienc Rural 38: 2587-2592

Sherwin CM, Richards GJ, Nicol CJ 2010: Comparison of the welfare of layer hens in 4 housing systems in the UK. Brit Poultry Sci 51: 488-499

Sonntag WI, Golze S, Spiller A, von Meyer-Hofer M 2018: There ain’t no such thing as a free lunch: Intrasustainable trade-offs in broiler production from a consumer's perception. Ger J Agr Econ 67: 31-47

Stark KDC, Alonso S, Dadios N, Dupuy C, Ellerbroek L, Georgiev M, Hardstaff J, Huneau-Salaun A, Laugier C, Mateus A, Nigsch A, Afonso A, Lindberg A 2014: Strengths and weaknesses of meat inspection as a contribution to animal health and welfare surveillance. Food Control 39: 154-162

Van Staaveren N, Doyle B, Manzanilla EG, Diaz JAC, Hanlon A, Boyle LA 2017: Validation of carcass lesions as indicators for on-farm health and welfare of pigs. J Anim Sci 95: 1528-1536

Webster AB 2004: Welfare implications of avian osteoporosis. Poultry Sci 83: 184-192 